\title{
La ocupación de la Araucanía y la pérdida de la platería en manos mapuches. Finales del siglo XIX y primeras décadas del $\mathrm{XX}^{1}$
}

por

\author{
Jaime Flores Chávez
}

Universidad de La Frontera

\begin{abstract}
La expansión del Estado chileno hacia la Araucanía, a partir de mediados del siglo XIX, generó un fuerte impacto sobre la economía mapuche. La bonanza ganadera del periodo preocupacional dio paso a una situación de postración económica que caracterizará la etapa post-ocupacional. Centrado en la platería como expresión reveladora de estos dos momentos, nuestro trabajo busca analizar el contexto y mecanismos que posibilitaron la pérdida de la plateria en manos mapuches a fines del siglo XIX y principios del XX. Para ello utilizaremos documentos notariales, informes militares, censos, periódicos, guías comerciales y diarios de viajes, entre otros.
\end{abstract}

Palabras Clave: Araucanía; mapuches; platería; Chile.

\section{INTRODUCCIÓN}

La expansión del Estado chileno hacia la Araucanía, a partir de mediados del siglo XIX, es un proceso que ha ocupado el interés de un importante número de especialistas. Aspectos militares, políticos, económicos, sociales o culturales, entre otros, han sido analizados desde perspectivas de tiempos largos y cortos. El ámbito espacial de estos trabajos ha transitado desde el

${ }^{1}$ Este artículo forma parte del proyecto Fondecyt No 1095052 denominado "Empresarios de la Araucanía, 1900-1960" del cual el autor es co-investigador y el investigador responsable es Jorge Pinto. 
estudio de comunidades, al estudio de territorios más amplios, como la macrorregión de la Araucanía y la Pampa.

En el ámbito económico, aspecto que nos interesa para los propósitos de nuestro trabajo, se constata el impacto sobre el pueblo mapuche del proceso ocupacional. Reducción de tierras, pérdida de la masa ganadera, campesinización forzada, desplazamientos internos y emigración a los centros urbanos son, entre otros, algunas de sus manifestaciones más significativas. Causa y expresión de la fuerte pauperización de los mapuches a partir de fines del siglo XIX.

Posicionados en una perspectiva histórica, nuestro trabajo busca analizar esta transformación centrando la mirada en la platería mapuche, un aspecto que devela el antes y el después de este pueblo marcado por la ocupación de su territorio. Si bien la platería ha cautivado el interés de especialistas de la artesanía, la estética y la simbología, existe una carencia de análisis a partir de la historia ${ }^{2}$.

A nuestro juicio, la platería fue una de las expresiones más observable del dinamismo y bonanza alcanzada por la economía mapuche en el periodo preocupacional, particularmente producto del comercio ganadero. La confección, evolución y acumulación de piezas de plata constituyó una expresión de la riqueza y poder alcanzado por caciques y ulmenes. Asumimos que la pérdida de estas piezas de plata fue expresión de la precariedad económica por la que comenzó a transitar el pueblo mapuche en el periodo post-ocupacional. Por ello nuestra atención estará centrada en develar el traspaso de la platería desde manos mapuches hacia manos wingkas ${ }^{3}$, hacia fines del siglo XIX y en las primeras décadas del siglo XX, buscando descubrir los mecanismos involucrados en este proceso. En base a bibliografía especializada y fuentes dispersas y fragmentarias se construye la historia que buscamos mostrar.

\section{La Ocupación de la Araucanía y el Impacto en la Economía Mapuche}

La expansión de la frontera agrícola chilena hacia la Araucanía iniciada a mediados del siglo XIX adquirió mayor fuerza con la refundación de Angol

\footnotetext{
${ }^{2}$ Al respecto ver Reccius, 1983: 17-31. El trabajo de Reccius permite informarnos sobre la evolución de esta platería desde el siglo XV al XX, con profusión de detalles respecto a la modificación y aparición de piezas en la platería mapuche. Para un estudio más amplio sobre la platería colonial en Chile ver De la Lastra, 1985. Sobre los detalles de las piezas de plata mapuche ver Morris, 1997; 1992; 1987. Joseph, 2006; 1928. Fontecilla, 1946. Aldunate, 1983. Schindler, 1985: 32-37. Domeyko, 2006. Molina, 2007.

${ }^{3}$ Entenderemos por wingka, el no mapuche, ya sea chileno o de otras nacionalidades.
} 
(1862), y la creación de las líneas militares del río Traiguén (1878), el río Cautín (1881) y la Cordillera de los Andes (1883). Esta última fecha marcaría la derrota militar mapuche. En paralelo, se iba desplegando la dinámica económica capitalista en La Frontera. Las tierras despejadas para el cultivo por los nuevos habitantes aumentaron aceleradamente ${ }^{4}$.

Antes que la agricultura, la ganadería desarrollada por los mapuches era la actividad que estructuraba la economía de la Araucanía. Sin embargo, para el período de nuestro estudio, ésta ya no era dominante ni los mapuches sus principales gestores. Los años de guerra y agitación en La Frontera habían causado graves efectos en la economía ${ }^{5}$. Las dos últimas décadas del siglo XIX $\mathrm{y}$ las primeras del XX dan cuenta de un incremento de la masa ganadera, consecuencia del aumento de la demanda del mercado local y nacional (ciudades y centros mineros). Para 1934-5 los departamentos ubicados entre Angol y Villarrica contribuían con el $16,8 \%$ de vacunos en el total nacional, el aporte más significativo recaía en el departamento de Temuco (29,1\%). A la luz de las cifras registradas en los pasos cordilleranos, pareciera que los antiguos circuitos entre la Araucanía y Neuquén continuaban activos aunque en un grado menor que en los viejos tiempos.

No obstante, la ganadería no era privativa de los grandes productores. Entre los medianos y pequeños constituyó una actividad significativa para el desarrollo de sus proyectos económicos. Además del autoconsumo, estos sectores se articulaban generalmente a los mercados locales y regionales y, en algunos casos (por medio de las ferias ganaderas) al mercado nacional. Hacer negocios a medias pasó a ser una estrategia necesaria para quienes poseían escasos recursos ${ }^{6}$.

Después de las incursiones militares iniciadas en la década del sesenta, que tuvo sus momentos más intensos entre 1868-1872 con la llamada «guerra de

${ }^{4}$ Sobre la transformación económica de la Araucanía en el periodo, ver los trabajos de Bengoa, 1985; 2004. León, 1991; 2007. León, Herrera, Parentini y Villalobos, 2003. Pinto, 2009. Flores, 2006.

${ }^{5}$ Por ejemplo, la industria de textiles indígenas se vio fuertemente impactada, sobre todo si consideramos su importancia en el periodo anterior. Respecto de la economía colonial mapuche y los textiles ver Pinto, 2003, en particular las pp. 24 a 34.

${ }^{6}$ Un ejemplo de ello fue la sociedad que establecieron Alberto Figueroa y Artemio Curihual, en la cual el primero daba al segundo 44 ovejas madres y dos carneros, «en medias» «de crianza i de lana». El plazo de la sociedad era de dos años. El acuerdo establecía que, cada año, los socios se repartirían el 50\% «de la crianza y de la lana», agregando que, en caso de pérdida, Curihual debía pagar a Figueroa \$20 por cada oveja. Si moría algún animal debía ser comprobado con el cuero y la señal, y entregárselo a Figueroa sin cargo alguno para Curihual. Sociedad entre Alberto Figueroa y Artemio Curihal, Archivo Regional de la Araucanía (ARA), Fondo Notarios de Nueva Imperial (FNNI), 1924, vol. 53, tomo I, folios.7-7v. 
recursos» y en 1881 con el levantamiento general, la situación de los mapuches pasó a un estado de verdadera miseria. En 1882 Gregorio Urrutia, comandante del Ejército del Sur, presentó su memoria al ministro de Guerra ${ }^{7}$. En ella efectuó una evaluación de los animales existentes en la Araucanía, comparándolos con los que esta región tenían en 1860. El resultado fue decidor, en 22 años los bovinos habían disminuido un $80 \%$, los caballares un $53,4 \%$, los ovinos un $71,4 \%$, los caprinos un $50 \%$ y los porcinos un $33,4 \%{ }^{8}$. Para los mapuches estas cifras resultaban más dramáticas si tenemos en cuenta que en 1882, el mayor porcentaje del ganado se encontraba en manos de los nuevos habitantes.

A juicio del militar, esta notable disminución de la masa ganadera de la Araucanía podía ser explicada porque desde 1860, las diferentes expediciones que se realizaron al interior del territorio mapuche habían capturado y traído a los fuertes fronterizos grandes cantidades de animales de diversos tipos. A esto se debía agregar el autoconsumo mapuche, la venta que estos realizaban a los comerciantes $\mathrm{y}$, principalmente, la situación de guerra que se vivía en ambos lados de la cordillera y que desde hacía años impedía a los mapuches importar ganado desde Argentina.

Añadía Urrutia que «los indios están verdaderamente pobres, i que la necesidad los obligará a dedicarse al cultivo de la tierra, de la que deben esperarlo todo sino quieren perecer de hambre», alimentándose, en los últimos años, de vegetales silvestres. La pobreza era generalizada en las comunidades mapuches. Una de las que visitó Urrutia, compuesta por 46 familias, no tenía más que 14 caballos, 16 vacunos y 130 cabezas de ganado lanar; y, como ésta, había muchas al norte del Cautín, sostenía el militar.

El estado de necesidad, reflexionaba el coronel, era el causante de los frecuentes robos que hacían los mapuches a sus «vecinos españoles» y entre los propios indígenas. En una expedición que comandó hacia las tierras comprendidas entre los ríos Cautín y Muco, buscando reprimir a un grupo de mapuches que habían robado, se internó hasta las cercanías del volcán Llaima. El militar quedó impresionado de la miseria en que vivían allí y procedió a repartirles trigo, frijoles y arvejas. Calculó unos 2.000 a 3.000 los mapuches que habitaban dichos parajes los cuales se alimentaban de «yerbas con agua i sal» y aún esto último les faltaba?.

\footnotetext{
7 "Memoria del Comandante en Jefe del Ejército del Sur, sobre la marcha administrativa i militar de la frontera en el último año, Santiago, junio 22 de 1882", Memoria del Ministerio de Guerra y Marina, 1882: 189-206.

${ }^{8}$ Según esta fuente, en términos absolutos el ganado había disminuido de 230.000 a 65.000 cabezas.

9 Correspondencia del Cuartel General Ejército del Sur 1882-1883. De Gregorio Urrutia a Ministro de Guerra, Angol, octubre 10 de 1882, Archivo Histórico Nacional, Santiago, Ministerio de Guerra, vol. 1045, sin número de foja.
} 
Era tal la crudeza de esta situación que en 1883 la Intendencia del Ejército del Sur recibió la orden de otorgar «raciones de víveres a todos los (indígenas) que no pudieran procurarse por sí mismos los alimentos necesarios para su subsistencia». Se priorizó a los mapuches pobres de los alrededores de cada fuerte, muchos de ellos en «estado de estrema pobreza». Durante los meses de noviembre y diciembre de aquel año se repartieron víveres a 12.606 indígenas. Para 1884, año del informe, se estimaba que la situación sería la misma e incluso peor. Un buen número de familias de la cordillera, «en un estado verdaderamente lamentable», habían llegado a pedir socorro al fuerte de Curacautín, después de que se le agotaran los «frutos silvestres» con los que se alimentaban ${ }^{10}$. El informe no daba cuenta de la Araucanía en su totalidad, sólo de aquellos puntos donde el ejército tenía almacenes ${ }^{11}$.

Si bien la postración económica en que habían quedado los mapuches era generalizada, esto no implicaba que fuera homogénea. Por la prolongación y características de las campañas es de presumir que las agrupaciones arribanas, así como aquellas reducciones que participaron activamente en el alzamiento de 1881, se encontraran en un estado de mayor precariedad económica. También aquellos ubicados en la Cordillera de los Andes y que basaban su economía en el ganado y la movilidad espacial, situación que el conflicto bélico dificultaba enormemente.

\section{LA PLATERÍA MAPUCHE, EVOLUCIÓN Y SIMBOLISMO}

Las investigaciones efectuadas por Walter Reccius ${ }^{12}$ (uno de los más reconocidos estudiosos de la platería mapuche), le permitieron afirmar que antes de la llegada de los españoles, los mapuches conocían el uso de los metales y manufacturaban adornos de cobre, al igual que de oro y plata ${ }^{13}$. Sin embargo

\footnotetext{
10 "Memoria del Intendente del Ejército del Sur. Angol, mayo 15 de 1884", Memoria del Ministerio de Guerra y Marina, 1884: 226-227.

${ }^{11}$ En términos de las identidades territoriales mapuche éstos se encontraban localizados en las antiguas tierras de los huenteches o arribanos (Victoria, Quino, Quillem, Lautaro, Pillanlelbún, Temuco) nagches o abajinos (Traiguén y Nueva Imperial) y los que habitaban algunos kilómetros al sur del Cautín (Freire). "Memoria del Intendente del Ejército del Sur. Angol, mayo 15 de 1884", Memoria del Ministerio de Guerra y Marina, 1884: 226-227.

12 Reccius, 1983: 17-31. El trabajo de Reccius permite informarnos de la evolución de esta platería desde el siglo XV al XX, con profusión de detalles respecto a la modificación y aparición de piezas en la platería mapuche.

${ }_{13}$ Tomás Guevara sostiene que el desarrollo de la platería entre los mapuches sería con posterioridad a la llegada de los españoles, quienes habrían introducido a los indígenas en
} 
fue con posterioridad a la llegada del español cuando esta práctica se intensificó. Reccius identifica cuatro etapas por las que abría pasado la orfebrería mapuche. La primera, desde la llegada del conquistador hasta el siglo XVIII, estaría marcada por una mayor profusión del trabajo de los metales, reducido a la confección de prendedores y aretes. Una segunda etapa, desde comienzos del siglo XVIII hasta principios del siglo XIX, estaría caracterizada por la producción de joyas de mayor complejidad usadas por las mujeres y por la aparición de aperos de montar, cinturones, bastones de mando y otras prendas usadas por los hombres. Una tercera etapa, desde principios del siglo XIX hasta fines de este siglo, en la que aparecen nuevas piezas de mayor complejidad, a la vez que se modifican muchas de las ya conocidas. Por último, una cuarta etapa a fines del siglo XIX en la que la producción de los objetos de plata es cuantiosa, se confeccionan nuevas piezas y se modifican otras.

Por su parte Raúl Morris, coleccionista y estudioso de la platería mapuche, identifica dos grandes momentos. El primero transcurriría entre 1600 y 1840 , a partir de ésta fecha, y hasta 1870 el joyero de la mujer mapuche cambió iniciándose la segunda etapa ${ }^{14}$. Según Morris por estos años se cambian los adornos de chaquiras por alhajas de plata, es un periodo de transición. Así, la segunda mitad del siglo XIX sería el momento de mayor enriquecimiento de la platería ${ }^{15}$. Otro tanto ocurre con los aperos de los caballos y adornos o aplicaciones en algunos utensilios de los jinetes, muy apreciados por los caciques y mapuches en general, como herrajes, riendas, frenos, variedades de espuelas, estribos, chicotes, etc.

Sin duda que, en la sociedad mapuche, la platería no sólo constituyó una forma de acumulación de riqueza, también poseía una significación ritual, y su posesión constituía un signo de poder y prestigio. Al respecto María Kangiser señala que los objetos de la platería mapuche tenían una connotación ritual y sacra, antes que un sentido utilitario; eran verdaderos documentos que nos informan sobre aspectos ideológicos ligados, estrechamente, a la religiosidad.

Esta investigadora observa que las mujeres visten sus joyas en ocasiones de importancia ritual, como entierros, rogativas de guillatún, por ejemplo. Así, las alhajas, en alguna medida, se transforman en «talismanes protectores y símbolos propiciadores de la fertilidad, entrecruzándose en su misterio con la tierra, la mujer y los dioses» ${ }^{16}$. Por su parte Natascha Wever sostiene que

este oficio. Al respecto ver Tomás Guevara, 1925: 362; 1908: 104. Esta misma postura asume Arturo Fontecilla, al respecto ver Fontecilla, 107 (Santiago de Chile, 1946): 247-271.

${ }_{14}$ Esto estaría asociado a la aparición de nuevas monedas como analizaremos más adelante.

15 Morris, 1997: 55.

${ }^{16}$ Kangiser, 6 (Viña del Mar, 2002): 64. 
existen «joyas ceremoniales y joyas de uso cotidiano», entre las primeras encontramos el trarilonko y el trapelakucha, entre las segundas, el chawai (aro) iwekuwe (anillo) y tupu (alfiler) ${ }^{17}$. Estos elementos hacen aún más significativo el proceso que, en pocos años, implicó la pérdida de platería en manos de los mapuches.

Pero además, las piezas de plata eran signo de riqueza y poder. Gustave Verniory explica este aspecto:

Los hombres adornan también con ornamentos de plata los correajes de sus caballos, sus lanzas, sus huascas, los mangos de sus cuchillos. Le atribuyen gran valor a estas baratijas. Son para ellos títulos de nobleza. Marcan el estado social, el rango o el grado de riqueza de aquel que los lleva, y por consiguiente son el derecho al respeto de sus semejantes ${ }^{18}$.

En este sentido Tomás Guevara da cuenta como los mapuches, desde mediados del siglo XVII, fueron reemplazando los frenos y riendas de barbas de ballena por los de hierro y las estriberas y espuelas de madera, por las de metal: «Al correr el tiempo, cuando dispusieron de plata, los caciques consideraban indispensable usar de este metal todo el arreo de monta, como cabezadas, copas, estriberas i espuelas, manifestación de riqueza i autoridad que se perpetuó hasta el total sometimiento de la raza» ${ }^{19}$.

El hijo del cacique Juan Küdel se recordaba a principios del siglo XX que su padre «Poseía abundante ganado y bosques de manzanos. Tenía su cabalgadura completamente cubierta de plata y sus mujeres eran lujosas» ${ }^{20}$. Lo mismo expresa el testimonio que entrega el indígena Pascual Coña:

Estas alhajas de plata las lucían las mujeres indígenas especialmente cuando había fiestas. Los hombres casi no llevaban sobre sí prendas de plata. Solamente los caciques antiguos ceñían a veces su cabeza con un aro de plata. Pero todos los hombres ponían su orgullo en el arreglo de sus cabalgaduras. Tenían espuelas y estribos de pura plata y adornos de plata en las aciones (sic); además cabezadas ataviadas de plata, provistas de colgantes del mismo metal. También tenían incrustaciones de plata en las barbadas y adornados los bocados en ambos lados con unos discos de plata. Las riendas eran targeadas con plata. Así relumbraban sus caballos, cuando se dirigían a sus reuniones festivas; todos estos adornos eran obra de los joyeros indígenas ${ }^{21}$.

${ }_{17}$ Wever, 1992: 3. Artículo en red http://www2.estudiosindigenas.cl/trabajados/plateria. pdf. digitalizado por el Centro de Documentación del Instituto de Estudios Indígenas de la Universidad de La Frontera.

18 Verniory, 2001: 62.

19 Guevara, 1925: 362.

${ }^{20}$ Guevara y Mañkelef, 2002: 106.

${ }^{21}$ Coña, 1984: 215. 
Para la segunda mitad del siglo XIX la platería (alhajas y aperos) era abundante y un producto codiciado entre los mapuches. Las autoridades chilenas usaban piezas de este metal para agasajar a algunos caciques ${ }^{22}$. El comercio de los mapuches con indígenas de la pampa argentina incorporaba prendas de plata. Cuando Juan Küdel iba a pasear a la argentina donde sus amigos Sayweke, Kallfükura y su hijo Namunkura «llevaba de regalo objetos de plata y traía animales» ${ }^{23}$. También muchos de los habitantes de Maquehue «viajaban a la Argentina para vender mantas y adornos de plata» ${ }^{24}$. Otro tanto hacían los de Quepe cuando se desplazaban a las tierras del cacique Kallfükura, al otro lado de la Cordillera de los Andes, «Llevaban choapinos y platería para cambiarlos por animales» ${ }^{25}$. Este mismo, cuando se instaló en Salinas Grande, comenzó a recibir un «pago» en su calidad de cacique, siguiendo la costumbre establecida entre las autoridades argentinas y los caciques. Este «pago»o «sueldo» consistía en plata, ropa y alimentos ${ }^{26}$. Efectivamente, en la Pampa, las autoridades de Buenos Aires entregaban «prendas de plata» entre las raciones dadas a los caciques a cambio de la $\mathrm{paz}^{27}$. También la platería era una forma de pago otorgado a los jefes indígenas que oían a las partes en caso de pleito en el interior de las comunidades ${ }^{28}$.

\section{Los Plateros y la platería en la Araucanía}

Dentro de la sociedad mapuche, la orfebrería adquirió mayor trascendencia con la llegada del conquistador. Es indudable que el crecimiento de la riqueza mapuche, producto de un incremento del tráfico ganadero, tuvo su contraparte en el aumento del volumen y complejidad de la platería que se fue confeccionando. Un trabajo de estas características demandó ejecutores más especializados, así surge el retrafe ${ }^{29}$ o platero «el artífice por excelencia de los indígenas», advierte Guevara $^{30}$. La desconfianza que tenían del wingka fue otra razón más para tener a los plateros en su propio territorio, siendo reacios a comprar piezas fabricadas

\footnotetext{
${ }^{22}$ Para la revolución de 1851 José María de la Cruz envió de regalo unos herrajes de plata al cacique Mañil Huenu, aliado de éste en esta conflagración. Guevara y Mañkelef, 2002: 91.

${ }^{23}$ Guevara y Mañkelef, 2002: 107.

24 Ibidem: 118.

25 Ibidem: 127.

${ }^{26}$ Lenz, 1895-97: 365.

27 Zeballos, 1993: 57.

${ }^{28}$ Guevara y Mañkelef, 2002: 143.

${ }^{29}$ Denominación que se le daba en mapudungun. La desconfianza que tenían los mapuches de los wingkas fue otra razón más para tener a los plateros en su propio territorio, además, desconfiaban mucho de las piezas de plata que provenían fuera de la Araucanía.

${ }^{30}$ Guevara, 1908: 104.
} 
fuera de la Araucanía o por orfebres que no eran de su confianza. Edmond Smith observó a un cacique negociando con un par de comerciantes quienes habían extendido sobre un poncho «numerosos pesos fuertes y espuelas de plata» que pensaban cambiar por el ganado del indígena. El cacique «Examinó cada artículo con el mayor cuidado, oliéndolo y probándolo con la lengua, haciéndolo sonar para constatar la pureza del metal. Por fin sacó de su cinturón una pequeña balanza de caña con platillos de cuero, procedió a pesar los artículos uno por uno, usando como norma unos pesos fuertes que llevaba sobre su persona $\rangle^{31}$.

Es de suponer que el mayor dinamismo de la economía, trajo aparejado el incremento de la platería y con ello la necesidad de aumentar el número de retrafes en la Araucanía. Además, su importancia se acrecentó de tal modo que en algunos casos llegaron a ocupar cargos de relevancia política en la sociedad mapuche, tal es el caso de los caciques Quilapán y Painemilla ${ }^{32}$.

La demanda de estos artefactos fue tanta que algunos jefes indígenas tenían su propio platero encargado de confeccionar joyas y aperos para engalanar a sus mujeres y caballos. Al respecto Tomas Guevara sostiene que «los caciques opulentos tenían en sus casas uno de estos peritos (retrafe), que le fabricaban toda la colección de la joyería indígena, tan en armonía con la vanidad indígena de los jefes bárbaros» ${ }^{33}$. El cacique Wenchu, importante líder de la zona de Angol «poseía las más grandes yeguas. Manejaba plateros y pelloneros» ${ }^{34}$. Lorenzo Kolüpi, también tenía platero y poseía un cuarto donde guardaba la platería al que podían entrar sólo las dos esposas preferidas ${ }^{35}$.

Uno de los encuentros más notables del viajero alemán Pablo Treutler fue con el importante cacique Paillalef de Pitrufquén. Aprovechando que este no se encontraba, recorrió y examinó el rukahue ${ }^{36}$ del jefe indígena. Una de las construcciones la había destinado para uso exclusivo de «su platero» y en nota a pie de página especificó «Es costumbre entre los araucanos (mapuches) que cada cacique de importancia tenga su platero exclusivamente dedicado a trabajar adornos para él i sus mujeres» ${ }^{37}$.

31 Smith, 1914: 103-104.

32 Para el caso de Quilapán ver Lenz, 1895-97: 365-366. Para el caso de Painemilla nos basamos en la entrevista oral que efectuamos a Rufino Painemilla en Lago Budi el 20 de abril de 2000.

33 Guevara, 1908: 104.

${ }^{34}$ Guevara y Mañkelef, 2002: 33.

35 Ibidem: 59.

${ }^{36}$ En mapudungun la ruka es la vivienda mapuche y rukahue, el lugar donde se ubica un conjunto de rukas.

37 Treutler, 1861: 191, «la Tierra» era una de las denominaciones dada a la Araucanía que también era conocida como La Frontera. 
El relato de Pascual Coña ilustra respecto de la dimensión e importancia de la platería mapuche y el oficio de retrafe. Ya anciano recordaba que, en tiempos antiguos (probablemente anteriores a 1840), las indígenas no poseían muchas alhajas de plata; tenían el prendedor tupu y los pendientes. Más numerosas eran las chaquiras. Luego esto cambió, las chaquiras ya no eran muy valoradas, en cambio las joyas de plata adquirieron mayor estimación. Como éstas fueron altamente demandadas, aparecieron los orfebres encargados de su confección. Entre los plateros, Coña recordaba en un sector del Lago Budi, lugar donde él residía, a Lorenzo Loncomilla de Rauquenhue, «Venancio el platero» de Ahueyuco, Montero Puen de Choncoye, Curín de Huapi o Nahuelhuen de Collileufu, entre otros ${ }^{38}$. Según el testimonio de Coña estos plateros confeccionaban pequeños crisoles de piedra que templaban en el fuego:

Adentro de estos vasos se echaban puñados de pesos y chauchas de plata y los asentaban sobre el carbón encendido de la forja. Además aplicaban el fuelle, por medio del cual atizaban las brasas alrededor del crisol lleno de plata. El vaso se acaloraba hasta ponerse candente y la plata del crisol se fundía. También arreglaban dos cajoncitos que contenían arena. Esa arena era el material para modelar... cualquier artefacto que querían fabricar ${ }^{39}$.

Una vez quitado el molde perfeccionaban el objeto con lima y martillo sobre el yunque. De esta manera procedían los plateros a confeccionar cualquier prenda de plata:

Así trabajan los integrantes de plata para las diversas vendas y cintas de la cabeza: los hemisferios para las cintas de las trenzas; los colgantes de estas cintas: ya largas, llamadas quilquil, ya cortas, de nombre trolol. Así hacían los aseguradores de las trenzas, los broches (las partes de plata) de las fajas que suspenden las trenzas en la nuca y los enlaces del pelo en las espaldas. De la misma forma confeccionaban los plateros los cuellos de plata, las cúpulas o realces de los collares, los colgantes grandes del pecho, los prendedores punzón y tupu, el siquil, trapelacucha y cruselis, los anillos y los muy variados zarcillos ${ }^{40}$.

La platería que lucían las mujeres en forma de joyas y los varones en los aperos de su caballo fue algo que atrajo la atención de los viajeros que incursionaron por la Araucanía. Al respecto Pablo Treutler, escribe:

Los atavíos que tanto desdeñan los hombres por ser contrarios a su carácter, gustan mucho a las mujeres que van siempre cubiertas de chaquiras i otros adornos

${ }^{38}$ Coña, 1984: 212. Habría que señalar la existencia de un número considerable de plateros, ubicados al norte del río Bío-Bío y otros instalados en las tierras mapuches, muchos de ellos chilenos.

39 Ibidem: 213.

40 Ibidem: 214. 
de plata. Entre estos merecen notarse una especie de carabanas (sic) de dicho metal, en forma de planchas, que tienen como tres pulgadas cuadradas i son por consiguiente bastante pesadas i alargan en extremo las orejas. Cuando salen de sus casas acostumbran usar también una especie de mantilla prendida sobre el pecho con un alfiler de plata de un pié de largo cuyo botón es del tamaño de una manzana regular ${ }^{41}$.

En su viaje por La Frontera, Treutler asistió al entierro de un cacique: «Desde mui de mañana empezaron a llegar los convidados de uno i otro sexo en hermosas cabalgaduras adornadas con cabezadas, frenos i estriberas de plata, luciendo las mujeres en sus cabezas, orejas i brazos adornos del mismo metal» ${ }^{42}$. El viajero quedó admirado con la llegada, al funeral, del cacique Quitrulef «ataviado de numerosas prendas de plata entre las cuales se hacían notar sus espuelas, la vaina de su espada (de fabricación enteramente indígena, i ria a machote) $\mathrm{i}$ una multitud de otras zarandajas de que estaba enjaezado su caballo. La montura era tanto o mas rica en platería que lo demás, i su valor no bajaría a mi juicio de trecientos pesos» ${ }^{43}$.

La sorpresa de Teutler fue mayor con ocasión de la visita al cacique Paillalef. Luego de mostrarle el corral con sus mejores animales lo «llevó a su casa de lujo, en donde me mostró todas sus riquezas, que consistían en prendas de plata, muchos pares de espuelas, vainas de sables, platos, fuentes, cucharas, mates, bombillas, puñales, cuchillos, etc. haciendo particular ostentación de una bolsa de cuero de chivato que contendría mas o menos tres mil pesos en monedas de oro i plata sellada, que por primera vez veía en mis peregrinaciones en la Tierra» ${ }^{44}$. Aclara Treutler que estas monedas eran el fruto de la venta de animales. Añade que, los mapuches prefieren las monedas de plata antes que las de oro que «funden para hacer sus alhajas i las de sus mujeres». Para ellos el oro, puntualiza Treutler, era la principal desgracia de sus antepasados.

Por su parte Smith va dando cuenta de las alhajas que lucen las mujeres y los aperos de plata de los caballos, en su recorrido por la Araucanía. Al respecto registra que al ingresar a la vivienda de Chancay Hueno «estaban suspendidos espuelas, frenos y estribos de plata, prendedores, zarcillos, collares de cuentas y numerosas otras zarandajas destinadas a aumentar los encantos de la dueña de casa ${ }^{45}$. Otro tanto ocurre al llegar a las posesiones del cacique

41 Treutler, 1861: 53.

42 Ibidem: 107.

43 Ibidem: 153. El mismo Treutler nos informa que, por esa misma fecha, un vacuno de uno a dos años tenía un valor de 75 centavos en Pitrufquén y 4 pesos en el mercado de Valdivia. Esto nos lleva a señalar que con los atavíos de plata a que hace referencia Treutler se podía adquirir entre 75 y 400 vacunos, dependiendo del lugar donde fueran comprados.

${ }^{44}$ Ibidem: 192.

45 Smith, 1914: 116. 
Mañil Huenu donde observa que «colgada de la ramada había una brida, con freno, cabezada y riendas, cubiertas de adornos de plata maciza; y aunque Mañin se consideraba pobre, doscientos pesos fuertes no habrían pagado todo el metal que vi en los aperos que usaba para montar a caballo» ${ }^{46}$.

\section{EL COMERCIO Y LAS MONEDAS DE PLATA}

Si bien es posible que los mapuches explotaran algunas vetas de plata, el mayor suministro provenía, primero, de los españoles y, después, de los chilenos. Candelabros, copones, bandejas y otros utensilios de este metal eran parte del botín que lograban los indígenas en sus malones ${ }^{47}$. También los «agasajos», dados por las autoridades con el propósito de mantener la paz, contenían piezas de plata como los bastones con «casquete de plata» que se le daban a los caciques ${ }^{48}$. Pero sin duda las monedas de plata constituían la principal materia prima para los plateros de la Araucanía, fruto de la venta de ganado y ponchos ${ }^{49}$. Durante el siglo XVII los mapuches usaban monedas de 8 reales, 4 reales, 2 reales, 1 real y hasta cuartillas. Las monedas «macuquinas» también eran admitidas. En el siglo XIX aparecieron los pesos, chauchas, dieces y cincos. Los plateros preferían las monedas menudas a los pesos y 8 reales y poco les gustaba los «trozos de plata porque eran más difíciles de fundir» ${ }^{50}$.

El comercio fronterizo entre indígenas y wingkas era intenso. Claudio Gay señala: «Los indios reciben la plata chilena, pero no la intercambian más, guardan esta plata para hacerse espuelas y ornamentos $\rangle^{51}$. Edmond Smith advierte el importante volumen de monedas de plata que es utilizada por los retrafes efectuando el siguiente cálculo «Si suponemos que trafican con los indios, dos a tres mil personas y estimamos que cada uno de ellos dispone anualmente de veinte o treinta pesos en moneda de plata, se puede ver fácilmente la considerable dificultad que causa la sustracción de esta cantidad de la circulación de una zona no muy poblada ni muy rica». A su juicio esta sería la causa de que «siempre hay escasez de sencillo en todas las provincias fronterizas» ${ }^{52}$.

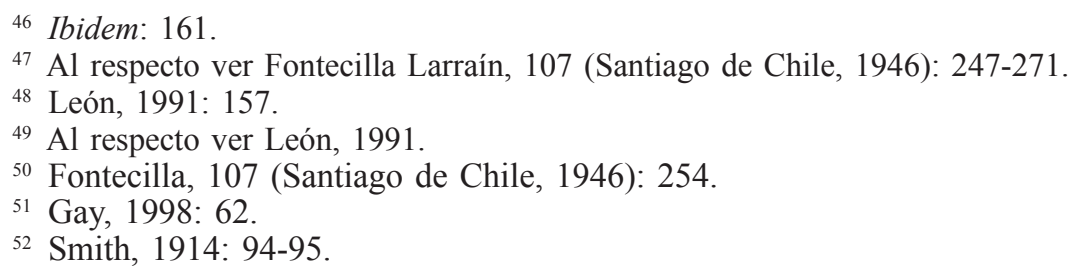


A petición de los plateros los mapuches preferían la moneda «menuda» a las grandes. El ingeniero belga Gustavo Verniory observa esta situación a propósito de la compra de huevos a los mapuches. Por dos monedas de cinco centavos recibía dos docenas, pero si pagaba con una de diez centavos le daban menos de 20 y agrega: «Nuestros amigos indios transforman las monedas en dijes y joyas, y para ellos valen más dos piezas de 5 que una de diez» ${ }^{53}$.

En efecto, no es del todo aventurado vincular la extraordinaria modificación de la platería mapuche de que dan cuenta especialista como W. Reccius, C. Joseph y R. Morris a mediados del siglo XIX, con los cambios experimentados en las monedas de platas acuñadas a partir del establecimiento de la república, particularmente con la adopción del sistema métrico decimal que implicó un cambio completo en nuestras monedas, materializado a través de la ley del 9 de enero de 1851. Esta ley, promulgada por el presidente Manuel Bulnes, en el artículo $2^{\circ}$ establecía la existencia de cinco clases de monedas de plata con una ley de «nueve decimos fino», estas eran de un peso, cincuenta, veinte, diez y cinco centavos respectivamente ${ }^{54}$.

La mayor dinámica de la economía nacional había hecho necesario acuñar moneda fraccionaria. Por ello a las de oro, se agregaban las de plata y cobre. En el caso de las de plata, que por la naturaleza del artículo son las que nos interesan, en el período que va entre los años 1851 a 1900 se acuñaron un total de 25.594.949 piezas de cinco centavos, 20.852.884 de diez centavos, 54.969.912 de veinte centavos, 5.363.612 de cincuenta centavos y 30.958.124 de un peso, lo que implica un total de 137.739 .481 piezas de plata ${ }^{55}$. Sin embargo en el periodo de 1810 a 1851 estas sumaban 7.779.286 ${ }^{56}$ y de 1772 a 1809 la cantidad de piezas de plata acuñadas en la Casa de Moneda de Santiago alcanzó un total de $13.552 .980^{57}$.

En base a las cifras aportadas era de esperar que, con el aumento de monedas de plata en circulación, particularmente a partir de 1851, asociado

53 Verniory, 2001: 409.

${ }^{54}$ La ley establecía que el peso contendría quinientos granos setecientos sesenta y ocho milésimos, o sea veinticinco gramos, y se dividiría en cien centavos; la de cincuenta centavos, contendría doscientos cincuenta granos trescientos ochenta y cuatro milésimos; la de veinte centavos con cien granos ciento cincuenta y tres milésimos; la de diez centavos con cincuenta granos setenta y seis milésimos; y la de cinco centavos con veinticinco granos treinta y ocho milésimos. Medina: 1902: CCIX.

55 Ibidem: 222. Sobre las monedas chilenas Luis Covarrubias publicó un extenso trabajo titulado "Monedas chilenas desde la independencia hasta la fecha", aparecido en cinco números (18-22) de la Revista Chilena de Historia y Geografia. En este estudio se entrega, esencialmente, la misma información que estamos citando en Medina.

${ }^{56}$ Medina, 1902: 220.

57 Ibidem: 219. 
a un activo comercio ganadero entre wingkas y mapuches, se incrementara el potencial de «materia prima» disponible para ser convertida en alhajas y aperos por los plateros de La Frontera, y por aquellos ubicados al norte del río Bío Bío ${ }^{58}$.

\section{El TRASPASO DE LA PLATERÍA HACIA LOS WINGKAS}

\section{El interés por la adquisición de platería mapuche}

Hacia la segunda mitad del siglo XIX emerge un importante mercado por los objetos indígenas. Para el caso que nos ocupa, la platería mapuche atrajo un interés local, nacional e internacional. En la sociedad que se instalaba en La Frontera existía inquietud por adquirir estas piezas. Algunos sujetos las compraban y cambiaban directamente a los mapuches para formar colecciones privadas. Gustavo Verniory señala que desde Talcahuano envió a Bruselas «una gran caja llena de curiosidades del país (entre ellas), una cantidad de joyas indias de plata: anillos, collares, pendientes, grandes agujas, etc.» ${ }^{59}$.

Pedro Doyharcabal, importante comerciante y agricultor de la zona, que en 1928 residía en Temuco, se destacaba por ser «coleccionista de antigüedades $\mathrm{u}$ objetos de arte araucano... Especialmente sobre joyas e indumentarias de indios mapuches de esta región», había formado una de las más valiosas colecciones del país ${ }^{60}$. Esto fue confirmado por Oreste Plath, para quien la colección de platería de Doyharcabal, producto de treinta años de «vinculaciones diarias con los indígenas», era considerada como la más completa de Chile ya que contenía piezas de gran valor por su antigüedad, la selección, cantidad y singularidad ${ }^{61}$.

El mismo autor destaca a Elena Montero Riveros, viuda de Leiva, como una de las más respetadas coleccionistas y realizadoras de importantes ex-

58 Es necesario precisar que hasta 1895 las monedas eran de 0,9 décimos de fino, salvo en 1891 en que se acuñaron monedas de hasta 0,2 décimos de fino. A partir de esa fecha las monedas eran de 0,5 decimos de fino hasta que con el correr de los años éstas fueron completamente de níquel y cobre.

59 Verniory, 2001: 443.

${ }^{60}$ Escobar, 1926: 592.

${ }^{61}$ Por ello muchas instituciones científicas extranjeras se interesaron por adquirirla, pero finalmente pasó al Museo de Arte Popular Americano de la Universidad de Chile. Tal era el prestigio de la colección de Pedro Doyharcabal que buena parte de las investigaciones de $\mathrm{H}$. Claude Joseph se sustentó en ella. 
posiciones mapuches en Sevilla y París. Ella había «obsequiado una gran colección de chilenidad al Museo del Trocadero, que estaba por esa época sin mostrar nada de Chile». Además, había estimulado la exposición de artículos indígenas en los hoteles de lujo de Chile, coleccionando una "gran cantidad de piezas mapuches de plata». Añade Plath que interesantes colecciones de platería araucana se conservaban en museos como: el Histórico Nacional, de Historia Natural, de Arte Popular Americano de la Universidad de Chile; Araucano de Temuco y Arqueológico de La Serena ${ }^{62}$.

Hacia la década de los 40 del siglo XX, Arturo Fontecilla constataba la partida de piezas de plata a museos nacionales y del extranjero. En el caso del Museo Nacional de Historia Natural, señalaba este autor que gracias al entusiasmo de su director, el Museo «también posee un buen lote de estas alhajas, todas auténticas, por que el señor Latcham, que es un inteligente arqueólogo y etnólogo, las ha sabido clasificar» ${ }^{63}$. Así mismo escribía Fontecilla que cuando el turismo conoció a los mapuches, para los extranjeros era «moda llevar objetos de plata araucana, ya sea para exponerlos en los museos o en las vitrinas de los salones», algo inimaginable para los artífices de esas obras, sostenía el estudioso ${ }^{64}$. La demanda de este tipo de objetos era tal que habían aparecido, en Concepción y otros lugares, talleres de confección de joyas de níquel aceptadas por las mujeres mapuches, «eso sí que muchos comerciantes, turistas y viajeros se llevan las legítimas de plata que compran pagando buenos precios» ${ }^{65}$. Las piezas de platería originales partían a otras latitudes, a la Araucanía comenzaban a llegar las imitaciones de mala factura.

Frente a esta demanda, el robo, la profanación de tumbas, la venta y el empeño de prendas de plata constituyeron las vías más frecuentes por las cuales la riqueza de la platería transitó desde la sociedad mapuche hacia particulares o instituciones wingkas radicadas en Chile y en el extranjero. Por el análisis de la documentación es posible pensar que su intensidad fue mayor en el periodo inmediatamente posterior a la derrota militar mapuche, años estos de extraordinaria pobreza, precaria instalación estatal y explosiva presencia de nuevos habitantes en la región. En este contexto, en algunos casos, las prendas de plata eran una forma de lograr una rápida fortuna.

\footnotetext{
62 Plath, 2001: 399-417.

${ }^{63}$ Se refiere a Ricardo Latcham director entre 1928 y 1943. Fontecilla, 93 (Santiago de Chile, 1938): 93.

${ }^{64}$ Fontecilla, 107 (Santiago de Chile, 1946): 247-248.

65 Ibidem: 252.
} 


\section{El botín y el robo}

En los malones que se daban entre mapuches la platería formaba parte del botín. Por ejemplo, el que dio Kolüpi a Lligllan del sector de Chankiñ «llevó animales y la plata ${ }^{66}$, o el que diera Koñuepang a Lienan donde los partidarios del primero se «Llevaron plata (adornos) y como doscientos animales» ${ }^{67}$. Sin embargo, las piezas continuaban en propiedad de los mapuches, cosa distinta comenzó a ocurrir a partir del proceso de ocupación, momento en el que la platería pasó a manos wingkas y en un volumen importante abandonó el territorio de la Araucanía.

En el caso de los robos, Raúl Morris efectuó un detallado estudio del asalto perpetrado al cacique Huenul en 1856, ocasión en la que le fueron substraídas un considerable número de piezas de plata ${ }^{68}$. La ocupación chilena del territorio indígena y la consecuente llegada de bandoleros a la Araucanía, intensificó el asalto a los mapuches, y si bien el objetivo principal era el robo de ganado, la platería también atrajo su interés. Ello explica una serie de asaltos ocurridos, en 1888, en algunas reducciones indígenas próximas al poblado de $\mathrm{Chol} \mathrm{Chol,}$ entre otros a Juan Huaiquin, ocasión en que los bandidos se llevaron «todas las prendas de plata que tenía» e hirieron gravemente a éste ${ }^{69}$. La captura de otro grupo de bandoleros, en los alrededores de Temuco, permitió recobrar un botín que incluía bueyes, monturas, saquetes con balas de carabina y «varias piezas de plata» ${ }^{70}$.

Las fuerzas militares desplazadas en el antiguo territorio indígena, también contribuyeron a esta pérdida patrimonial mapuche. La figura del botín de guerra no estuvo ausente en la Araucanía ${ }^{71}$. En el contramalón generado a propósito del levantamiento mapuche de 1881, se capturó gran cantidad de

${ }^{66}$ Guevara y Mañkelef, 2002: 201.

67 Ibidem: 103.

${ }^{68}$ Morris, 1997. Aunque esto ocurrió en una fecha temprana para el estudio que estamos efectuando, demuestra el interés que la platería despertaba como botín en la Araucanía.

69 "Chol Chol. Correspondencia para El Imperial", El Imperial, 18-08-1888: 2. "Chol Chol”, El Imperial, 18-08-1888: 3; "Galvarino", El Imperial, 29-09-1888: 3. Los periódicos fueron consultados en la Biblioteca Nacional de Chile (BNCh).

70 "Crónica. Salteo", El Cautín, 27-03-1890: 2, BNCh. Respecto de la violencia en la Araucanía en el periodo post-ocupacional ver León, Herrera, Parentini y Villalobos, 2003, en particular el capítulo IV "Violencia inter-étnica en la Araucanía, 1880-1900": 181-270.

${ }^{71}$ En el lado argentino, las piezas de plata fueron parte del botín de los soldados en la Campaña del Desierto. En un asalto a una toldería Prado recuerda: «Cuando llegamos nosotros, los milicos estaban llenando las maletas con lo que hallaban a mano: frenos, riendas, estribos de plata; ponchos, matras, cojinillos; facones, boleadoras, espuelas», Prado, 1977: 92. 
ganado y prendas de plata. Pascual Coña relata que al llegar a una zona montañosa encontraron a un grupo de mujeres que al verlos comenzaron a gritar pensando que les darían muerte, lo cual no ocurrió «solamente se las despojó de sus prendas de plata, también de sus espuelas y estribos de plata que llevaban consigo en gran número». Del botín entregaron la mitad a Painemilla y la otra la escondieron. Coña sostiene que «Painemilla juntó mucha plata, llenó un saco y se lo guardó» ${ }^{72}$. Por su parte, el cacique Calfuqueu, que había participado en la rebelión indígena, se presentó ante Painemilla para someterse, llevándole «prendas de plata como precio de rescate y reconciliación» ${ }^{73}$. Lo reunido por Painemilla habría sido entregado al jefe militar a cargo de la represión contra los alzados ${ }^{74}$. Según el relato que venimos siguiendo, los caciques Huichal, Colihuinca y Millahuinca concurrieron donde el Gobernador a pedir las paces trayendo «sus alforjas llenas de objetos de plata... El Gobernador se tomó las prendas de plata e hizo encadenar a los caciques». Unos días más tarde los habría sacado de la cárcel y pasado por las armas ${ }^{75}$.

\section{La profanación de tumbas}

Entre los ritos que practicaban los mapuches estaba el de enterrar a los muertos con algunas de sus piezas de plata. Refiriéndose a esta práctica, el cronista Diego de Rosales sostiene que, los mapuches, entre otras cosas «les ponen a los difuntos en las sepulturas los mejores vestidos que tenían en vida, las joyas y las armas para que peleen ${ }^{76}$. La misma observación que efectúa el jesuita Gómez de Vidaurre en el siglo XVIII cuando señala que «Las mujeres lo visten después con sus mejores vestidos $\mathrm{i}$ joyas» ${ }^{77}$.

Siglos más tarde el naturalista Claudio Gay señala que en el entierro del cacique Melín se hicieron dos hoyos, en uno se enterró al cacique y en el otro «se arrojo a uno de sus caballos con estribos, silla y arnés» ${ }^{78}$. Es de presumir que dichas prendas estaban confeccionadas en plata. Este mismo autor agrega que «cuando una mujer muere una parte se sus joyas son enterradas con ella

${ }^{72}$ Coña, 1984: 283-284.

73 Ibidem: 1984: 285.

${ }^{74}$ Los testimonio recogidos por el autor entre los descendientes del cacique Painemilla apuntan a que esta habría sido una forma de pago a cambio de la devolución del ganado confiscado a los mapuches y para evitar mayores castigos.

${ }^{75}$ Coña, 1984: 286.

${ }^{76}$ Citado por Medina, 1952: 262.

77 Citado Guevara, 1908: 263.

78 Gay, 1998: 72. 
las demás son heredadas por las niñas» ${ }^{79}$. Por su parte Ruiz Aldea escribe que en el caso de fallecer un cacique mapuche, es enterrado con los objetos «que más había amado; allí le ponen una montura completa, sus armas y varias prendas de plata, algunas viandas, un caballo muerto y hasta un gallo para que le cante las horas» ${ }^{80}$. A finales del siglo XX, el mapuche Alejandro Leninao Quidel recordaba que cuando moría un cacique «se le echa su caballo ensillado cuando ya va a ser enterrado... Este asunto era así antes. Todo lo que le pertenecía, sus objetos de plata, todo se le echaba al muerto» ${ }^{81}$. Por lo demás, esto mismo ratifican las excavaciones más contemporáneas ${ }^{82}$.

Este ritual ancestral atrajo el interés de los wingkas desde los tiempos de la conquista. Conocemos la profanación de tumbas como una práctica llevada adelante por los españoles, en búsqueda de oro ${ }^{83}$. Esto continuó en los siglos siguientes, intensificándose con posterioridad a la ocupación de la Araucanía hacia fines del siglo XIX, en esta ocasión con la búsqueda de piezas de plata $\mathrm{y}$ otros artefactos indígenas.

La profanación de tumbas llevó a los mapuches a incorporar algunas variantes en sus rituales mortuorios. Edmond Smith, viajero norteamericano que visitó la Araucanía a mediados de siglo XIX, señala que aquellos enterraban a sus muertos con «sus armas y atavíos; pero los objetos de valor, espuelas $\mathrm{y}$ frenos de plata son generalmente sustituidos por otros de madera» ${ }^{84}$. Hacia finales del mismo siglo, Gustave Verniory da cuenta de este cambio en el ritual funerario, observando que antes los cadáveres eran enterrados con sus objetos preciosos y provisiones, además se encendía un fuego «que servirá al muerto para calentarse en su futura existencia». De tiempo en tiempo se renovaban las provisiones y se volvía a encender el fuego. Agrega que «Esta era la costumbre cuando los indios eran los únicos amos en el país. Ahora que han penetrado allí los chilenos y colonos extranjeros, temen el robo de los objetos dedicados al servicio del muerto y los entierran inmediatamente con él ${ }^{85}$. A este respecto resulta elocuente el testimonio proporcionado por Francisco Grin, pastor protestante que visitaba a los colonos suizos recientemente

79 Ibidem: 79.

${ }^{80}$ Ruiz, 1902: 47. http://www2.estudiosindigenas.cl/trabajados/araucanos_i_costumbres.pdf

${ }^{81}$ Kuramochi y Huisca, 1997: 400.

${ }^{82}$ Ernesto de Moesbach encontró una sepultura que contenía osamentas humanas, vasos cerámicos y pendientes de plata. Coña, 1984: 413. Por su parte Américo Gordon efectuó la excavación de un cementerio mapuche, entre los adornos y artefactos personales encontrados hay aros, «tupus» o alfileres de plata, al respecto ver Gordon, Madrid y Monteleón, 1973: 501-514.

${ }^{83}$ Al respecto ver Medina, 1952: 259 a 279.

${ }^{84}$ Smith, 1914: 86-87.

85 Verniory, 2001: 71. 
llegados a la Araucanía. Uno de ellos lo «conduce a la cumbre de una colina, donde hubo antes un cementerio indio. Las tumbas han sido abiertas por los chilenos, en busca de objetos de plata con los que se adornan los araucanos, a todos los caciques fallecidos» ${ }^{86}$. El mismo Verniory profanó un cementerio a pocos kilómetros al sur de Temuco, de allí extrajo «una especie de ídolo, más bien un monumento funerario», que posteriormente formaba parte de la decoración de su casa en Bruselas ${ }^{87}$.

Tomás Guevara, conocedor de esta práctica, señalaba que los mapuches eran celosos respecto de la tumba de sus mayores, toda vez que éstas habían sido «profanadas desde la dominación española hasta la república por los buscadores de entierros. Agregando que, estas profanaciones exasperaban al araucano i ahondaban su rencor profundo a la raza antagónica» ${ }^{88}$.

\section{La venta y el empeño}

Como hemos señalado anteriormente, la ocupación militar y las transformaciones que vivía la Araucanía, generó un periodo marcado por la escasez alimentaria en el pueblo mapuche. Además, la producción de alimentos generada por los indígenas no era suficiente para suplir sus necesidades. Una vía para mitigar esta situación fue la venta y el empeño de su platería. En el caso de los comerciantes, la adquirían para luego venderla por piezas o colecciones ${ }^{89}$. Este fue un comercio que tempranamente se instaló en La Frontera. Lo exótico de las joyas mapuches era llamativo para extranjeros y nacionales, más aún si se asumía que era una etnia en extinción. Estos artefactos, así como sus producciones textiles, cerámicas, vegetales y todo cuanto proviniera de su cultura pasaban a ser piezas de colección, que constituían un mercado de características singulares ${ }^{90}$.

A su paso por Concepción, en 1887, el pastor Grin recorrió la ciudad observando que «No lejos de la estación, en la calle Comercio, se encuentra un

${ }^{86}$ Grin, 1987: 149.

87 Verniory, 2001: 415.

${ }^{88}$ Guevara, 1908: 276.

89 Algunos comerciantes emborrachaban a los ancianos caciques para que estos sacaran las piezas de plata que tenían ocultas en la ruka y con ellas pagaran el licor que estaban bebiendo, Fontecilla, 107 (Santiago de Chile, 1946): 257. Gustave Verniory confiesa haber utilizado esta práctica para procurarse objetos de plata, Verniory, 2001: 62.

${ }^{90}$ En este sentido resulta ilustrativo el testimonio dado por Raúl Morris respecto de la génesis de la colección de platería mapuche de la que él era propietario. En su opinión, «el conjunto de joyas antiguas más numeroso que existe en el mundo». Morris, 1987. 
almacén de curiosidades que pertenece a un alemán. Algunos adornos indios, de plata, y especimenes de historia natural despiertan mi interés. Desgraciadamente los precios son inaccesibles ${ }^{91}$.

Años más tarde, en el Anuario Comercial Hispano-Chileno de los años 1924-1925 se anunciaba que García Hnos., propietario de la tienda y bazar «El Globo» y del «Banco del Pobre» de Temuco, tenía a la venta «gran variedad de joyas de oro y plata, ropa hecha, calzado, sombreros, alhajas y tejidos mapuches ${ }^{92}$. En esta misma ciudad, otro tanto ocurría con la tienda «La Bienhechora» cuyo propietario era Atilano García y Cía., que, además de poseer artículos generales para caballeros y niños, novedades para señoras y una gran existencia de mercaderías surtidas; y además de comprar y vender toda clase de cueros, tenía una «exposición permanente de toda clase de artículos de manufactura araucana y de objetos de los naturales de la región» con ventas en el país y en el extranjero ${ }^{93}$, ilustrando el aviso con fotografías del exterior e interior del negocio, además del dibujo de una pareja de indígenas y diversos artefactos mapuches ${ }^{94}$. Hacia 1933 esta tienda había pasado a manos de Martínez, Rueda y Cía. prosiguiendo con la venta de «toda clase de antigüedades araucanas» ${ }^{95}$.

Para 1921 El propietario de «La Bienhechora» era Esteban Hiriart. En aquel año se publica en el periódico local, una entrevista que ilustra el lucrativo negocio de la compra y venta de objetos mapuches, en particular de platería. El empleado que fue entrevistado informaba que el establecimiento se había especializado en la venta de objetos indígenas desde su fundación hacia 1900. El cronista de esta entrevista relata lo que ve al entrar a sus dependencias:

En una colocación ordenada y artística, se presentan a nuestros visitantes hermosísimos objetos de plata, trabajo auténtico de los indios; frenos, riendas, estribos, joyas de todas clases, grandes prendedores, aros, etc., no faltando esplendidas mantas, choapinos, fajas, pontros, y, en general, cuanto artículo haya sido usado por los indígenas. Nuestra sorpresa no tiene límites y ante ella, sonríe amablemente el señor García (el empleado de la tienda). Aparte de esto que pudiéramos llamar museo de antigüedades, señala el articulista, el señor García nos muestra grandes vitrinas atestadas de objetos sobre los cuales nos da explicaciones, indicándonos el uso a que los indios los dedicaban, la antigüedad, etc. ${ }^{96}$.

91 Grin, 1987: 87.

92 Aranda, 1924-1925: 262.

93 Ibidem: 252-253.

${ }^{94}$ El estudio de H. Claude Joseph respecto de la platería mapuche efectuado en 1930 incorporó las prendas que exhibía la tienda «La Bienhechora».

95 Arellano, 1933: 10.

96 "Las mejores colecciones de artículos y joyas araucanas", El Diario Austral, 0105-1921: 1. 
Este mismo empleado le informó al periodista que, a pesar de generar grandes ventas de artículos mapuches, su colección era la más completa de la región. En su opinión esto se debía a la rectitud con que trataban con los indígenas, «cuando obligados por las necesidades deben desprenderse de alguna joya u otro objeto antiguo» ${ }^{97}$. Agregaba que la alta demanda y el precio que alcanzaban estos objetos mapuches habían estimulado su falsificación. La opinión informada de García le permitía identificar a los coleccionistas más destacados de la región, señalando en primer lugar a Guillermo Aguiar, luego a Eliodoro Santander y a Pedro Doyharcabal, propietario de una «mediana colección» estimaba en unos $\$ 15.000^{98}$.

El entrevistado señalaba que esta tienda era muy visitada por los viajeros que llegaban a Temuco. Entre las visitas ilustres mencionaba al Príncipe Fernando de Baviera y Borbón, y al General alemán Von Litzman, quien adquirió varios objetos, manifestándoles que en Alemania no había observado ninguna de las especies que le eran mostradas. Hablaba además de una delegación de ferroviarios argentinos que compraron varias piezas para el «Museo de Buenos Aires». Agregaba que la tienda estaba preocupada por formar una completa colección de objetos indígenas para ofrecérsela al gobierno chileno, con el fin de que la depositara en el Museo Nacional. En verdad, la llegada de viajeros había estimulado la presencia de este tipo de tiendas pero «los precios eran muy subidos, en otros términos, muy de ocasión para turistas extranjeros» como lo constataba un turista nacional en $1933^{99}$.

Otro destino de la platería mapuche fueron las numerosas casas de empeño localizadas en los pueblos de la Araucanía. A pesar de que la lógica de este tipo de actividad era el «rescate» de la prenda por el propietario, es probable que solo un número reducido lograra recuperarla, debido a la situación económica en que se encontraba la población mapuche ${ }^{100}$. El trabajo de investigación sobre platería que efectúa $\mathrm{H}$. Claude Joseph, le permite afirmar que la necesidad llevaba al mapuche a empeñar sus prendas de plata por las que recibía el $50 \%$ de su valor. Estima que son «enormes» las cantidades de objetos de platas depositados en los «montes de piedad de Temuco». Y

97 Idem.

${ }_{98}$ Idem. Para hacernos una idea de lo que esta cifra implica, los $100 \mathrm{~kg}$. de trigo, puestos en Santiago, tenían un valor de $\$ 37$ y los $100 \mathrm{~kg}$. de porotos $\$ 31$. Datos obtenidos de la edición de El Diario Austral de Temuco, 8 de mayo de 1921, BNCh.

99 J. F. F. G., 1933: 38. (El autor de este libro solo se identifica con las iniciales de lo que presumimos son sus nombres y apellidos).

${ }_{100}$ H. Claude Joseph señala que las casas de préstamos de las ciudades del sur y las colecciones privadas habían sido uno de los destinos de los artefactos de plata de gran valor artístico, Joseph, 2006: 3. 
agrega que entre los mapuches existía gran desconfianza con los extraños que preguntaban por sus prendas de plata debido al robo de que eran objeto. Más aún, existían zonas donde los mapuches habían vendido todas sus joyas para no atraer la codicia de los ladrones.

En los primeros años, numerosas eran las casas de prestamos en la Araucanía. Una verdadera «plaga» que estaba presente en los pueblos de La Frontera, dice el Pastor Grin, agregando que «el préstamo con prenda lo ejercen todos cuando la oportunidad se presenta» ${ }^{101}$. El Anuario Prado Martínez de 1904 registraba: una casa de préstamo en Angol, propiedad de Agustín Morales ${ }^{102}$; otra en instalación en Los Sauces, propiedad de Pedro Méndez ${ }^{103}$; dos en Traiguén, de Alcibíades Mosqueira y Eduvigis Sanhueza v. de O. ${ }^{104}$; una en Perquenco, que se registra a nombre de Juan B. Queirolo, quien poseía, además, una cantina ${ }^{105}$; una en Collipulli, de Juan de D. Muñoz ${ }^{106}$; cuatro en Temuco cuyos propietarios eran Pantaleón Espinoza, Ismael Manríquez, Esegenio (sic) Michand y la sociedad de Fuenzalida y Janger ${ }^{107}$; y tres en el pueblo de Lautaro a nombre de Emilio Couchon, Juan Queirolo y Antonio Sangal ${ }^{108}$.

La Guía de Información Comercial e Industrial de Chile. Comercio, industria, agricultura, salitre y minería registra dos casas de prendas en Angol pertenecientes a Emilio Castro y Ramón Zúñiga ${ }^{109}$. En Traiguén éstas llegaban a cinco en manos de Pedro Bocaz, Miguel Campos, Fedreic Heguy, Nicomedes Iturra y Ramón Setuian ${ }^{110}$. Por su parte Alberto Manzan y Virgilio Vivanco desarrollaban este tipo de negocio en Valdivia ${ }^{111}$.

En 1912-1913 existían, por lo menos, tres casas de prendas en Temuco, cuyos propietarios eran: Burgos y Rodríguez, Esteban Hiriart y Tolosa e hijos ${ }^{112}$. E. Hiriart, de nacionalidad francesa, era dueño además de una tienda establecida desde 1906, en la que vendía ropa, calzado, artículos de talabartería y "surtido general de artículos de indígenas en tejidos $\mathrm{i}$ alhajas» ${ }^{113}$. Por su parte Tolosa e Hijos, españoles establecidos en 1906 en la ciudad, poseían

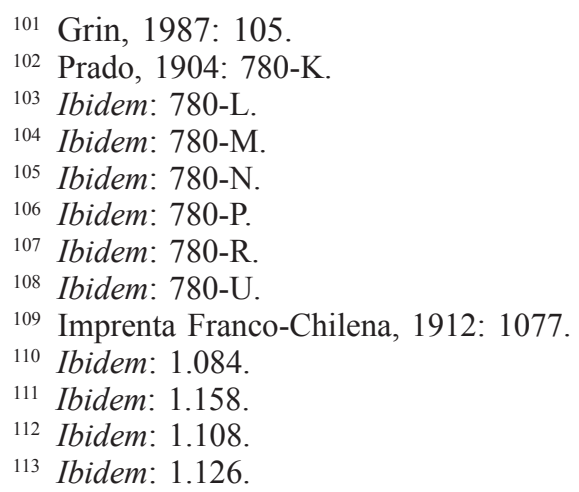


también una tienda especializada en artículos indígenas ${ }^{114}$. Los casos de Hiriart y Tolosa e Hijos nos permiten observar la asociación entre casa de préstamo y tienda en el negocio de los artículos mapuches, preferentemente de plata.

El negocio de las casas de préstamo se fue incrementando y formalizando dentro del espectro comercial. Para 1918, a las tres casas mencionadas en Temuco se agregaban otras dos, las de Arana Hnos. y Tapia y Cía., como registraba una guía comercial de aquel año ${ }^{115}$. Este mismo documento señalaba para Angol las casas de préstamos de María Elisonde y Ramón Zúñiga ${ }^{116}$. Traiguén aportaba las de Gabriel Garacoch, Rissetti Hnos., Setuian y Erostegui y la de Cantalicio Valdebenito ${ }^{117}$. En Victoria encontramos las de Olegario Fierro y Masana y García ${ }^{118}$, además estos últimos poseían un almacén de abarrotes señalado en la misma dirección. En Lautaro dos, la de Oviedo y Cía, y la de Cortés y Mellado, estos últimos poseía un almacén y tienda de mercaderías surtidas ${ }^{119}$. Por último, una en Nueva Imperial, de Silverio Conus ${ }^{120}$.

La Guía Universo de 1925-1926 registraba para Angol las casas de préstamos de Eduvigis v. de Fernández y otra de Beatriz E. v. de García; en Collipulli, Mario Galvarin; En Pailahueque, Manuel Sarazúa; en Traiguén, Felipe de la Sierra; en Lautaro, Carmela v. de Olivos; en Nueva Imperial, tienda y casa de préstamo García y Gutiérrez, y casa de préstamo La República de Francisco Mattas; en Puerto Saavedra, dos casas de préstamo y tiendas de Manuel de Miguel y Carlos Moisés; en Carahue, Francisco Matta; en Temuco, García Hnos. tienda y casa de préstamo y Gabriel García casa de préstamo ${ }^{121}$. En 1931 la agencia «El Tigre» de Tomás García T. tenía a la venta «toda clase de antigüedades araucanas», agregando que poseía el surtido más completo de toda La Frontera ${ }^{122}$.

Por lo expuesto, parece que el comercio de platería en la Araucanía era un negocio lucrativo. Comercio establecido y particulares vieron en la platería un espacio para hacer fortuna. En 1893 un articulista del periódico El Colono de Angol daba cuenta de este momento histórico cuando señalaba que:

No son pocos los comerciantes que han logrado constituir cuantiosa fortuna, durante los primeros años; Temuco i Nueva Imperial eran los dos mercados favoritos del indíjena (sic), quien a cambio de una cantidad insignificante de alcohol, de

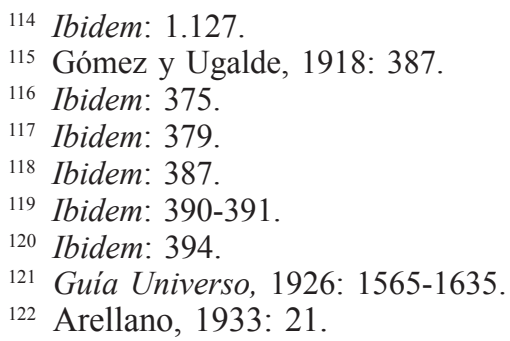


unas pocas varas de jénero, u otros artículos de que necesitaba surtirse, entregaba al afortunado vendedor, espuelas, aros, collares, arreos de silla para montar u otras prendas de plata de mui buena lei, que hacía subir a veces a sumas fabulosas el precio ínfimo de cualquier objeto manufacturado. Eran los tiempos de edad de oro; este jénero de especulación se hace en reducidísima escala, pues el araucano trafica en el día con el ganado mayor i menor, con las lanas, el lingue, trigo i demás productos agrícolas ${ }^{123}$.

\section{REFLEXIONES FINALES}

La segunda mitad del siglo XIX marca un momento trascendente en la Araucanía, generado por la expansión agrícola de Chile hacia el sur, proceso que se intensifica a partir de la derrota militar mapuche en 1883. La masiva llegada de nuevos habitantes, nacionales y extranjeros, conllevó una fuerte explotación de los recursos naturales existentes al sur del río Bío Bío. Fue un proceso intenso que cambió la base productiva de La Frontera. Como resultado, la actividad ganadera fue desplazada por la agricultura, particularmente cerealera; y la explotación forestal fue incrementándose a medida que se adentraba el siglo XX.

En este proceso, las acciones por parte de las fuerzas militares chilenas, el desplazamiento forzado, así como la reducción de las tierras mapuches fueron generando una acelerada disminución de la capacidad económica entre la población indígena que, en algunos sectores y momentos, alcanzó niveles dramáticos. A partir de este minuto, la campesinización forzada constituyó un proceso por el que debió transitar este pueblo. En este nuevo contexto, se hizo necesario cultivar más intensamente la tierra, transformar la mano de obra de los nuevos productores y salir a comerciar a los pueblos que iban surgiendo en la región.

Esta situación distaba mucho de lo que había ocurrido en el periodo preocupacional, donde el comercio ganadero desplegado por los mapuches había generado una importante riqueza reflejada, entre otras cosas, en el significativo desarrollo de su platería. Las fuentes permiten dar cuenta de este proceso en sus diversas etapas, siendo la más relevante la iniciada hacia mediados del siglo XIX, momento en que aumentó considerablemente el volumen de platería de los mapuches y se modificaron los diseños de dichas piezas. A

123 “Guía de La Frontera”, El Colono, 07-02-1893: 2, BNCh. También los periódicos informaban de remates en que, entre otros objetos, había «bombillas, espuelas de plata y muchos otros objetos indígenas del mismo metal». "Remate de prendas de plazo vencido. En la casa de préstamos El Araucano", El Cautín, 27-12-1898: 12, BNCh. 
nuestro juicio, la ley del 9 de enero de 1851, consecuencia de la adopción del sistema métrico decimal, constituyó un hito en la medida que generó cinco tipos de monedas de plata (correspondientes a un peso, cincuenta, veinte, diez y cinco centavos) que aumentaron ostensiblemente, la cantidad de circulante en el país. Esta ley, consecuencia de la mayor actividad económica alcanzada después de la independencia, incrementó la «materia prima» disponible para confeccionar piezas de plata. Por ello no es de extrañar que tanto Walter Reccius y H. Claude Joseph, como Raúl Morris señalen que hacia mediados del siglo XIX se abría producido un profundo cambio en los diseños de la platería mapuche; a lo que podemos agregar que también se produjo un aumento en el volumen de plata (piezas y monedas) en manos mapuches acumulada desde los siglos coloniales.

La ocupación de las tierras de La Frontera produjo un fuerte impacto en la platería mapuche. Reducidas sus tierras y ganado, la capacidad de generar riqueza se vio constreñida. Como consecuencia, se produjo un hecho excepcional: la confección de artículos de plata se redujo ostensiblemente y disminuyó también la calidad de los mismos. Paralelamente se fue conformando una importante demanda de objetos indígenas, en particular de su platería, por parte de coleccionistas nacionales y extranjeros, ya fuesen particulares o institucionales, como museos de diferentes índole y envergadura. para la obtención de estas piezas se movilizaron bandidos, comerciantes y particulares, entre otros. Este mercado de objetos mapuches estimuló la violencia en la Araucanía durante la ocupación y el periodo post-ocupacional. El «botín de guerra» se constituyó en una forma de extracción de la platería, también los robos a comunidades mapuches y la profanación de sus tumbas, obligándolos a modificar las prácticas de sepultación de sus muertos. En este contexto, el incremento de la pobreza los forzó a deshacerse de su platería con el propósito de obtener los bienes que necesitaban. Así, el empeño, el trueque y la venta de piezas de plata fue una práctica recurrente entre mapuches y wingkas en el periodo analizado.

Es indudable que esta dinámica tuvo como resultado una importante pérdida de la riqueza acumulada durante siglos por la sociedad mapuche, además de la casi desaparición de los plateros. ¿Cuál fue el volumen de plata que transitó desde estas comunidades hacia los nuevos dueños? Las fuentes no permiten dar una respuesta cuantitativa, ni siquiera estimativa. Sin embargo, a partir de las fuentes consultadas es de presumir que fue significativamente alto e incluso sería la base sobre la que se constituyeron algunas fortunas de la Araucanía. 


\section{BIBLIOGRAFÍA}

Aldunate, Carlos, "Reflexiones acerca de la platería mapuche", Carlos Aldunate y Walter Reccius, Platería Araucana, Santiago de Chile, Museo de Arte Precolombino, 1983: 10-15.

Aranda, Diego y Aranda F., Anuario Comercial Hispano-Chileno, Santiago de Chile, Imprenta Selecta, 1924.

Arellano, Oscar, El álbum guía histórico del cincuentenario de Temuco, Temuco, Imprenta Gutiérrez, 1933.

Bengoa, José, Historia del pueblo mapuche, siglos XIX y XX, Santiago de Chile, Sur, 1985.

Bengoa, José (comp.), La Memoria Olvidada. Historia de los Pueblos Indígenas de Chile, Santiago, Publicaciones del Bicentenario, 2004.

Coña, Pascual, Testimonio de un cacique mapuche, Santiago de Chile, Pehuén, 1984.

Covarrubias, Luis, "Monedas chilenas desde la independencia hasta la fecha", Revista Chilena de Historia y Geografía, 18 (Santiago de Chile, 1915): 161-185.

Covarrubias, Luis, "Monedas chilenas desde la independencia hasta la fecha", Revista Chilena de Historia y Geografía, 19 (Santiago de Chile, 1915): 281-305.

Covarrubias, Luis, "Monedas chilenas desde la independencia hasta la fecha", Revista Chilena de Historia y Geografía, 20 (Santiago de Chile, 1915): 444-470.

Covarrubias, Luis, "Monedas chilenas desde la independencia hasta la fecha", Revista Chilena de Historia y Geografía, 21 (Santiago de Chile, 1916): 453-495.

Covarrubias, Luis, "Monedas chilenas desde la independencia hasta la fecha", Revista Chilena de Historia y Geografía, 22 (Santiago de Chile, 1916): 83-124.

De la Lastra, Fernando, Platería colonial, Santiago de Chile, Ministerio de Educación, Departamento de Extensión y Cultura, 1985.

Domeyko Cassel, Jacqueline, Lágrimas de Luna. Tesoros de la platería mapuche, Santiago, Colección Domeyko Cassel, 2006.

Escobar, Aníbal, Anuario de la Colonia Francesa de Chile 1925-1926, Santiago de Chile, sin editorial, 1926.

Flores, Jaime, "Economías locales y mercado regional. La Araucanía, 1883-1935", Espacio Regional, 2/3 (Osorno, 2006): 11-28.

Fontecilla, Arturo, “Apuntes para la historia de la platería en Chile”, Revista Chilena de Historia y Geografía, 93 (Santiago de Chile, 1938): 52-98.

Fontecilla Larraín, Arturo, "La platería entre los araucanos", Revista Chilena de Historia y Geografia, 107 (Santiago de Chile, 1946): 247-271. 
Gay, Claudio, "Viaje a la Araucanía en 1863”, Iván Inostroza (ed.), Etnografía mapuche del siglo XIX, Santiago de Chile, DIBAM, 1998: 45-106.

Gómez y Ugalde, Anuario Sucesos 1918. Guía General de Chile. Informaciones generales de comercio, industria, importación, exportación, roles comerciales, industriales y profesionales, Valparaíso/Santiago de Chile, Sociedad Imprenta/ Litografía Universo, 1918.

Gordon, Américo, Madrid, Jacqueline y Monteleón, Julia, “Excavación del cementerio indígena en Gorbea (sitio GO-3). Provincia de Cautín. Chile", Actas del VI congreso de arqueología chilena, octubre de 1971, Boletín de Prehistoria, número especial 1972-1973 (Santiago de Chile, 1973): 501-514.

Grin, Francisco, Las colonias suizas de la Araucanía, Santiago de Chile, Grupo de Estudios Agro-Regionales, 1987.

Guevara, Tomás, Psicología del pueblo araucano, Santiago de Chile, Imprenta Cervantes, 1908.

Guevara, Tomás, Historia de Chile. Chile prehispánico, Santiago de Chile, Balcells y Cía., 1925.

Guevara, Tomás y Mañkelef, Manuel, Historia de familias. Siglo XIX, Santiago de Chile, Colibris, 2002.

Guía de Información Comercial e Industrial de Chile. Comercio, industria, agricultura, salitre i minería, 1912-1913, Santiago de Chile, Imprenta Franco-Chilena / Imprenta Sud-Americana, 1912.

Guía Universo. Índice General de la República de Chile 1925-1926, ValparaísoSantiago de Chile, Sociedad Imprenta Universo, 1926.

Joseph, H. Claude, "La platería araucana", Anales de la Universidad de Chile, 1 trimestre (Santiago de Chile, 1928): 119-158.

Joseph, H. Claude, Platería y vivienda araucana, Valdivia, Serindígena, 2006.

Kangiser, María, "Conservación en platería mapuche: Museo Fonck, Viña del Mar", Conserva, 6 (Santiago, 2002) http://www.dibam.cl/dinamicas/DocAdjunto_27.pdf (consultada en octubre de 2013).

Kuramochi, Yoseke y Huisca, Rosendo, Cultura Mapuche. Relatos, rituales y ceremonias, Quito, Abya-Yala, 1997.

Lenz, Rodolfo, Estudios araucanos, Santiago de Chile, Imprenta Cervantes, 1895-97.

León, Leonardo, Maloqueros y conchavadores en la Araucanía y las Pampas, 17001800, Temuco, Universidad de La Frontera, 1991.

León, Leonardo, Herrera, Patricio, Parentini, Luis y Villalobos, Sergio, Araucanía: frontera mestiza, siglo XIX, Santiago de Chile, Universidad Católica Cardenal Raúl Silva Henríquez, 2004. 
León, Leonardo, "Tradición y modernidad: vida cotidiana en la Araucanía (19001935)", Historia, 40/2 (Santiago de Chile, 2007): 333-378.

Medina, José Toribio, Las monedas chilenas, Santiago de Chile, Impreso y grabado en casa del autor, 1902.

Medina, José Toribio, Los aborígenes de Chile, Santiago de Chile, Fondo histórico y bibliográfico José Toribio Medina, 1952.

Memoria del Ministerio de Guerra y Marina, 1882, Santiago, Imprenta Nacional, 1882.

Molina, Joaquín, Mapuche. Arte de los pueblos del sur, Buenos Aires, Fundación Nicolás García Uriburu, 2007.

Morris, Raúl, Plata de la Araucanía. Colección Raúl Morris von Bennewitz, Talagante, Ilustre Municipalidad de Talagante / Museo Regional de la Araucanía, 1987.

Morris, Raúl, "Sistemática de las joyas araucanas. Los últimos doscientos años", Plateros de la Luna, Santiago de Chile, Biblioteca Nacional de Chile, 1988: 21-74.

Morris, Raúl, Platería mapuche, Santiago de Chile, Kactus, 1992.

Morris, Raúl, Plateros en la Frontera y la Platería Araucana, Temuco, Universidad de La Frontera, 1997.

Pinto, Jorge, La Formación del Estado y la nación, y del pueblo mapuche. De la inclusión a la exclusión, Santiago de Chile, DIBAM, 2003.

Pinto, Jorge, La Población en la Araucanía en el siglo XX. Crecimiento y distribución espacial, Temuco, Universidad de La Frontera, 2009.

Plath, Oreste, "Primacía y estirpe de los metales en Chile", Juan Antonio Massone (ed.), Homenaje a Oreste Plath (1907-1996). Una vida dedicada a Chile, Santiago de Chile, Universidad de Talca / Academia Chilena de la Lengua, 2001: 399-417. Originalmente este artículo fue publicado en Tradición. Revista Peruana de Cultura, 19-20 (Cuzco, junio 1955 - enero 1957).

Prado Martínez, Alberto, Anuario Prado Martínez, Unica Guía comercial, industrial, profesional y administrativa de Chile, Santiago de Chile, Centro Editorial de Alberto Prado Martínez, 1904.

Prado, Manuel, La guerra al malón, Buenos Aires, EUDEBA, 1977.

Reccius, Walter, "Evolución y caracterización de la platería araucana", Carlos Aldunate y Walter Reccius, Platería Araucana, Santiago de Chile, Museo de Arte Precolombino, 1983: 17-31.

Ruiz Aldea, Pedro, Los araucanos y sus costumbres, Santiago de Chile, 1902. http:// www2.estudiosindigenas.cl/trabajados/araucanos_i_costumbres.pdf (consultada en octubre de 2013)

Schindler, Helmut, "Silver jewelry of the mapuche", Ornament, 8/3 (San Marcos, California, 1985): 32-37. 
Smith, Edmond R., Los araucanos. Notas sobre una gira efectuada entre la tribus indígenas de Chile meridional, Santiago de Chile, Imprenta Universitaria, 1914.

Treutler, Pablo, La provincia de Valdivia y los Araucanos, Santiago de Chile, Imprenta Chilena, 1861.

Verniory, Gustave, Diez años en Araucanía 1889-1899, Santiago de Chile, 2001.

Wever, Natascha "Küme platañma domo: estudio preliminar acerca del uso y significado de las joyas femeninas mapuches" http://www2.estudiosindigenas.cl/trabajados/ plateria.pdf (consultada en octubre de 2013)

Zeballos, Estanislao, Callvucurá y la dinastía de los Piedra, Buenos Aires, Centro Editor de América Latina, 1993.

Fecha de recepción: 28 de diciembre de 2011.

Fecha de aceptación: 30 de mayo de 2012.

\section{The occupation of the Araucania and the mapuche's loss of their plattery by the end of XIX century and first decades of century XX}

The expansion of the Chilean state towards the Araucania region from the mid-nineteenth century had a major impact on the mapuche economy. The cattle bonanza of the pre-occupation period gave way to the economic malaise which characterized the post-occupation phase. Centring on the activity of silversmithing as a means of reflecting on these two periods, our study seeks to analyze the context and mechanisms which brought about the loss of silversmithing from mapuche hands in the late-nineteenth and early twentieth centuries. Sources used include notary documents, military reports, census information, newspapers, commercial guides and travel journals.

KEY WORDS: Araucanía region, mapuches, silversmithing, Chile. 